\title{
Virilising ovarian tumors: a single-center experience
}

\author{
Manjeetkaur Sehemby', Prachi Bansal', Vijaya Sarathi' ${ }^{2}$, Ashwini Kolhe ${ }^{3}$, Kanchan Kothari $^{3}$, \\ Swati Jadhav-Ramteke', Anurag R Lila', Tushar Bandgar' and Nalini S Shah' \\ 'Department of Endocrinology, Seth GS Medical College and KEM Hospital, Parel, Mumbai, India \\ ${ }^{2}$ Department of Endocrinology, Narayana Medical College, Nellore, Andhra Pradesh, India \\ ${ }^{3}$ Department of Pathology, Seth GS Medical college and KEM Hospital, Parel, Mumbai, India \\ Correspondence should be addressed to T Bandgar: drtusharb@gmail.com
}

\begin{abstract}
Literature on virilising ovarian tumors (VOTs) is limited to case reports and series reporting single pathological type. We have analyzed the clinical, hormonal, radiological, histological, management and outcome data of VOT. This retrospective study was conducted at a tertiary health care center from Western India. Consecutive patients with VOT presenting to our endocrine center between 2002 and 2017 were included. Our study included 13 patients of VOT. Out of 13 patients, two were postmenopausal. All patients in the reproductive age group had secondary amenorrhea except one who presented with primary amenorrhea. Modified $F$ and $G$ score (mFG) at presentation was $24 \pm 4.3$ and all patients had severe hirsutism ( $m F G \geq 15$ ). Change in voice $(n=11)$ and clitoromegaly $(n=7)$ were the other most common virilising symptoms. Duration of symptoms varied from 4 to 48 months. Median serum total testosterone level at presentation was $5.6 \mathrm{ng} / \mathrm{mL}$ with severe hyperandrogenemia (serum testosterone $\geq 2 \mathrm{ng} / \mathrm{mL}$ ) but unsuppressed gonadotropins in all patients. Transabdominal ultrasonography (TAS) detected VOT in all except one. Ten patients underwent unilateral salpingo-oophorectomy whereas three patients (peri- or postmenopausal) underwent total abdominal hysterectomy and bilateral salpingo-oophorectomy. Seven patients had Sertoli Leydig cell tumor, three had steroid cell tumor and two had Leydig cell tumor and one had miscellaneous sex cord stromal tumor. All patients had normalization of serum testosterone after tumor excision. In conclusion, VOTs present with severe hyperandrogenism and hyperandrogenemia. Sertoli Leydig cell tumor is the most common histological subtype. Surgery is the treatment of choice with good surgical outcome.
\end{abstract}

\author{
Key Words \\ - virilising ovarian tumor \\ - testosterone \\ - virilisation \\ - salpingo-opherectomy
}

\section{Introduction}

Ovarian tumor is an important cause of morbidity and mortality, especially in middle-aged women. Ovarian tumors are broadly classified into epithelial and nonepithelial tumors, of which epithelial tumors are common. Nonepithelial malignancies of the ovary account for less than $10 \%$ of all ovarian cancers (germ cell tumors: 5\%; sex cord stromal tumors: 3-5\%) (1). Less than half of these nonepithelial tumors secrete hormones which can produce either estrogenic or androgenic manifestations.

Hyperestrogenic manifestations are age dependent. Prepubertal girls usually present with gonadotropinindependent isosexual precocious puberty whereas women in reproductive age group or postmenopausal age present with irregular and excessive uterine bleeding (2). Hyperandrogenic (HA) manifestations include menstrual https://ec.bioscientifica.com

https://doi.org/10.1530/EC-18-0360
C) 2018 The authors Published by Bioscientifica Ltd
This work is licensed under a Creative Commons Attribution-NonCommercial-NoDerivatives 4.0 International License. 
abnormalities, hirsutism and varying degrees of virilization (temporal balding, deepening of voice, decreased breast size, increased muscle mass, loss of female body contours, clitoral enlargement (clitoral length $>10 \mathrm{~mm}$ )). Virilising ovarian tumor (VOT) is a rare cause of HA but HA is an important clue for the early diagnosis of these potentially malignant tumors. A prompt diagnosis of these potentially malignant ovarian tumors and developing an appropriate treatment strategy, considering multiple factors like patient age, stage of the tumor, histopathology and future fertility prospects, is essential. However, literature on hormone-secreting ovarian tumors is limited to case reports and series reporting single pathological type. In this study, we analyzed the clinical, hormonal, radiological, histopathological, management and outcome data of the VOTs.

\section{Methods}

This retrospective study was conducted at the Department of Endocrinology of a tertiary health care center from western part of India. Patients with histologically proven VOTs presented to our department between 2002 and 2018 were included in the study. Approval of this retrospective study with waiver of consent was obtained from Institutional Ethics Committee (IEC II) Seth GS Medical College and KEM Hospital. As a part of department protocol, informed consent for the photograph, publication of their clinical details and/or clinical image was taken at the time of presentation.
Case records of the patients fulfilling the inclusion criteria were reviewed and patient information including age of presentation, onset and duration of symptoms, clinical features (menstrual abnormalities, hirsutism and signs of virilisation), hormonal evaluation (folliclestimulating hormone (FSH), luteinizing hormone (LH) and testosterone), imaging details (transabdominal sonography, computed tomography/magnetic resonance imaging), surgical details and follow-up of the patients were collected.

Hormonal measurements were carried out by chemiluminescence assay (Advia Centaur CP). Intra-assay and inter-assay coefficients of variation were less than 8 and $10 \%$, respectively, for estimation of all hormones.

Statistical analysis was done using SPSS version 23. Categorical variables are expressed in actual numbers and percentages. Continuous variables are expressed as mean \pm s.D. or median and range. Continuous variables between the two groups were compared using independent $t$ test or Mann-Whitney $U$ test as appropriate whereas categorical variables were compared with Fisher exact $t$ test or chi-square test as appropriate. Correlation between two variables was calculated using Pearson's correlation coefficient $(r) . P$ value $<0.05$ was considered statistically significant.

\section{Results}

Our study included 13 patients of VOT. Out of 13 patients, two were postmenopausal. All patients in reproductive age group had secondary amenorrhea

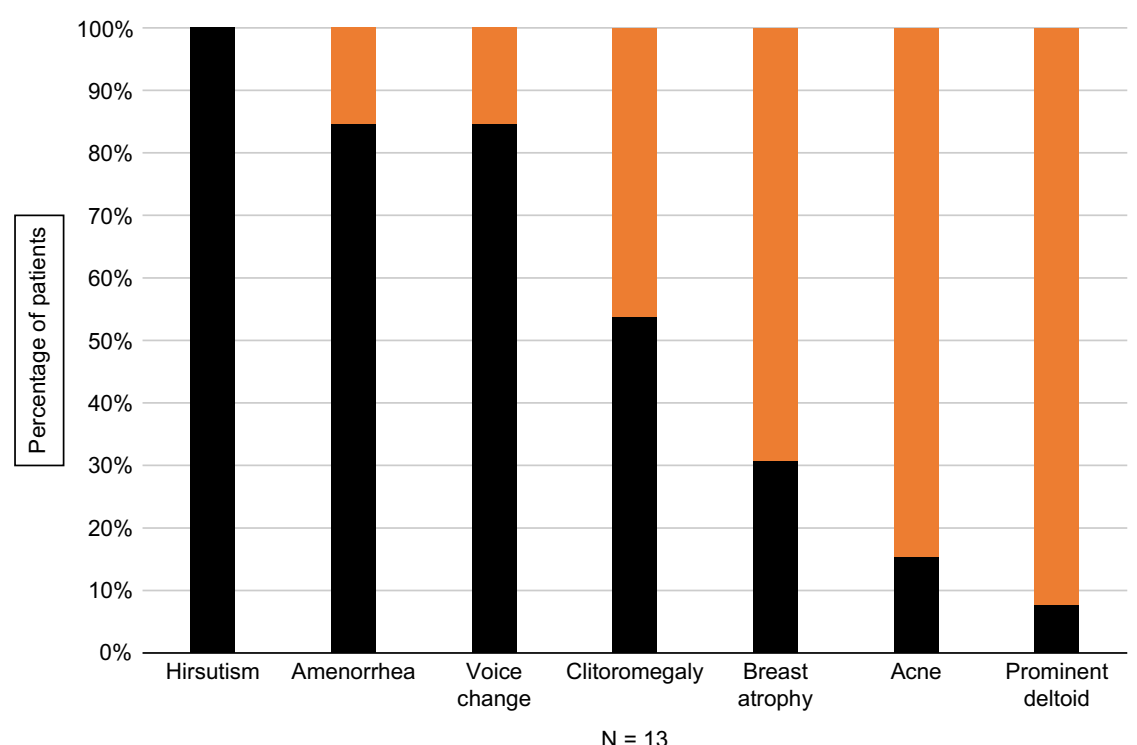

Figure 1

Percentage of patients with each symptom.

$$
\begin{array}{lr}
\text { https://ec.bioscientifica.com } & \odot 2018 \text { The authors } \\
\text { https://doi.org/10.1530/EC-18-0360 } & \text { Published by Bioscientifica Ltd }
\end{array}
$$


except one who presented with primary amenorrhea (Fig. 1). Out of the ten patients who presented with secondary amenorrhea, seven patients had history of preceding oligomenorrhea (median: 6 months; range: 4-18 months). Irrespective of age group, all patients presented with severe hirsutism (mean modified $F$ and $G$ score: $24 \pm 4.3$ ) (Figs $2 \mathrm{~A}$ and $3 \mathrm{~A}$ ). Varying degrees of virilisation was present in all patients (Table 1). Change in voice was present in $84.6 \%(11 / 13)$, clitoromegaly in $53.8 \%$ (7/13) patients (Fig. 3B), breast atrophy in 30.7\% $(4 / 13)$, acne in $15.4 \%(2 / 13)$ and prominent deltoid in $7.2 \%$ (1/13). Modified FG (mFG) score was significantly higher in patients with clitoromegaly than those without $(28.0 \pm 4.54$ vs $21.83 \pm 4.58, P=0.03)$. Breast atrophy was present in both postmenopausal women compared to only two of the eleven premenopausal women $(P=0.08)$. There was no significant correlation between any other clinical features of HA.

Duration of symptoms was variable ranging from 4 to 48 months. Median serum testosterone level was $5.6 \mathrm{ng} / \mathrm{mL}$ (range: $2.2>20 \mathrm{ng} / \mathrm{mL}$ ). Patients with acne had significantly higher serum total testosterone than those without $(12.8 \pm 10.18$ vs $5.45 \pm 2.33 \mathrm{ng} / \mathrm{mL}, P=0.03)$. Although the duration of symptoms was apparently lower in patients with acne than those without, it was statistically insignificant $(8.0 \pm 5.65$ vs $23.18 \pm 17.69$ months, $P=0.27)$. There was no significant correlation of duration of symptoms or serum total testosterone with any other clinical features of HA. FSH and LH were not suppressed in reproductive age women but were low-normal in postmenopausal ones.

As shown in Table 2, transabdominal ultrasonography (TAS) was the initial investigation in all patients suspected VOT. It detected lesions in all except two. Case no 3 had no evidence of neoplasm on TAS. She underwent transrectal sonography which showed a solid tumor. Case no 9 had undergone transvaginal sonography as the initial investigation (Fig. 2B). In other three patients, although ultrasound identified the ovarian tumors, missed the cystic $(n=2)$ or solid $(n=1)$ component of solid cystic tumors. Additional imaging in the form of either MRI and/or CT pelvis was done in all patients as a part of operative workup (Figs 3C and 4B). In most of the patients USG findings were confirmed on CT/MRI. The lesion was detected on CT in the patient who had normal TAS. CT detected an additional cystic component in a patient who had a solid tumor on TAS. CT and MRI missed cystic and solid component in one patient each which were detected on gross pathology. Maximum tumor diameter was $5.1 \pm 2.9 \mathrm{~cm}$. Maximum tumor diameter of solid cystic

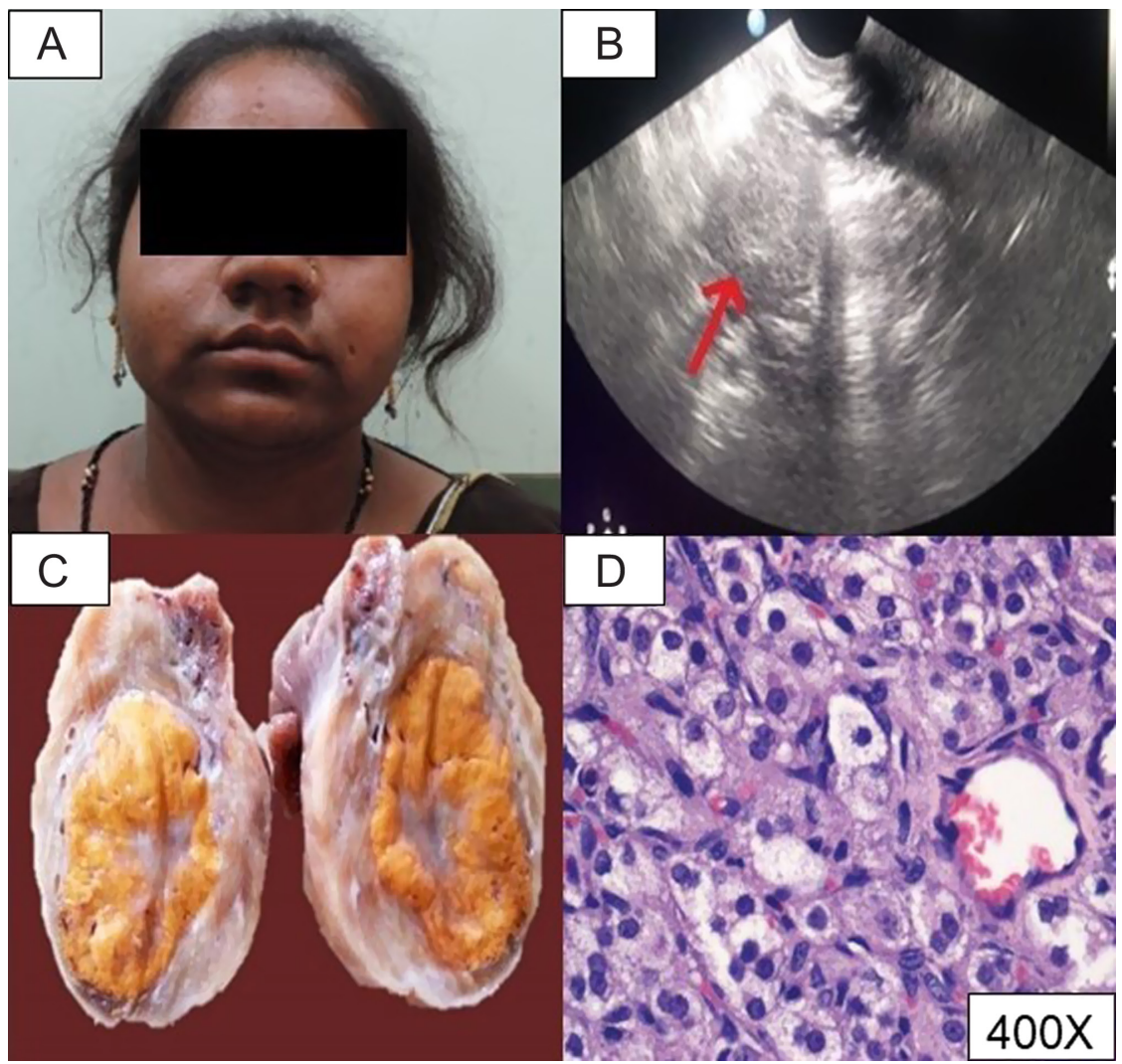

Figure 2

Steroid cell tumor: Hirsutism (A); transvaginal ultrasound: solid right ovary mass iso to hypoechoic having mild internal vascularity $(4.4 \times 3 \mathrm{~cm})(B) ; 5 \times 5 \times 4 \mathrm{~cm}$ circumscribed, yellow, lobulated tumor (C); microscopy: large polyhedral cells with vacuolated cytoplasm and smaller cells with eosinophilic granular cytoplasm in vascular stroma (400x) (D). https://ec.bioscientifica.com https://doi.org/10.1530/EC-18-0360 (c) 2018 The authors Published by Bioscientifica Ltd
This work is licensed under a Creative Commons Attribution-NonCommercial-NoDerivatives 4.0 International License. 
tumors was apparently higher than that of solid tumors but the difference was statistically insignificant $(6.76 \pm 3.84$ vs $3.67 \pm 0.39 \mathrm{~cm}, P=0.079)$. There were no significant differences in age, duration of symptoms, mFG, serum total testosterone and histology between solid and solid cystic tumors.

All patients except two (case no 4 and 9) underwent laparotomy. Case no 4 and 9 underwent laparoscopic excision. Ten patients underwent unilateral salpingo-oophorectomy whereas three patients (one perimenopausal and two postmenopausal patients) underwent total abdominal hysterectomy and bilateral salpingo-oophorectomy. None of the patients were given chemotherapy.

Seven patients had Sertoli Leydig cell tumor (Fig. 2A, B, C and D), three had steroid cell tumor (Fig. 3A, B, C, D and E) and two had Leydig cell tumor (Fig. 4A, B, C, D and $\mathrm{E}$ ) and one had miscellaneous sex cord stromal tumor (Fig. 5A and B). Patients with Sertoli Leydig cell tumors were significantly younger than those with Leydig cell tumors $(21.14 \pm 4.7$ vs $49.5 \pm 14.84$ years, $P=0.002)$ and had a tendency for lower mFG scores than those with steroid cell tumors $(24.43 \pm 3.3$ vs $30.67 \pm 6.02, P=0.06)$. No other correlations between clinical features and histological subtypes were significant. There was a significant positive correlation between serum total testosterone and tumor volume $(r=0.86, P=0.01)$.

Patients were followed up to a mean duration of $8.8 \pm 8.4$ months. In four patients, normalization of testosterone was documented in the immediate postoperative period (3-7 days) and was re-confirmed on follow-up at 3 months, whereas in all other patients, normal serum testosterone was documented after 3 months of surgery. On follow-up, all patients who presented with secondary amenorrhea resumed menses between 2 and 4 months after tumor excision. The lady with primary amenorrhea attained menarche 6 months after tumor excision. Modified $F$ and $G$ scores were reduced from $24 \pm 4.3$ to $13.4 \pm 3.8$ and $5.7 \pm 2.9$ at 6 months and 12 months after tumor excision respectively. Improvement in voice change was noted in three patients. All patients were alive at the last follow-up.

\section{Discussion}

We report the clinicopathological profile of 13 VOT cases from a single center. To the best of our knowledge, our series is one of the largest series of VOT and provides an overview of clinical presentation, hormonal abnormalities and management of this uncommon disorder.

HA commonly manifests as hirsutism which can be a presentation in common conditions like PCOS. In our series all VOT patients in the reproductive age presented with severe menstrual abnormalities (secondary amenorrhea or primary amenorrhea) whereas severe hirsutism (mFG >15) and at least one of the features of virilization (clitoromegaly, deepening of the voice and breast atrophy) were present in all patients. Hence, in any PCOS woman presence of one of these features should raise the clinical suspicion for VOT. Rapid onset and progression of hirsutism is a typical presentation of ovarian or adrenal androgen-secreting neoplasms (3). However, in our series, although majority had symptom duration

Table 1 Clinical and hormonal profile of patients with hormone-secreting ovarian tumors.

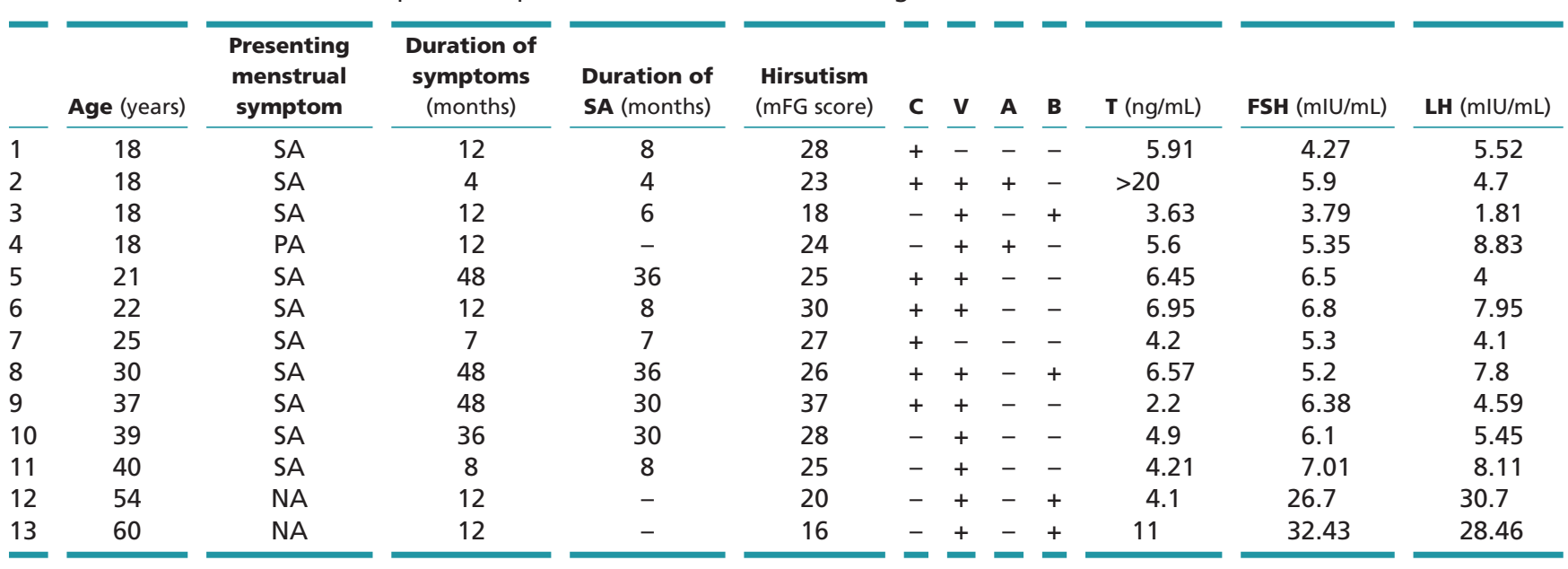

A, acne; B, breast atrophy; C, clitoromegaly; FSH, follicle stimulating hormone; LH, luteinizing hormone; mFG score, modified Ferriman Gallwey score; NA, not applicable; PA, primary amenorrhea; SA, secondary amenorrhea; T, testosterone; $\mathrm{V}$, change in voice.

https://ec.bioscientifica.com

https://doi.org/10.1530/EC-18-0360
(C) 2018 The authors Published by Bioscientifica Ltd

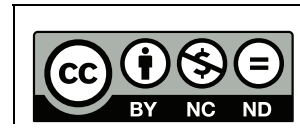

This work is licensed under a Creative Commons Attribution-NonCommercial-NoDerivatives 4.0 International License. 
Table 2 Radiology, histopathology and management of patients with hormone-secreting ovarian tumors.

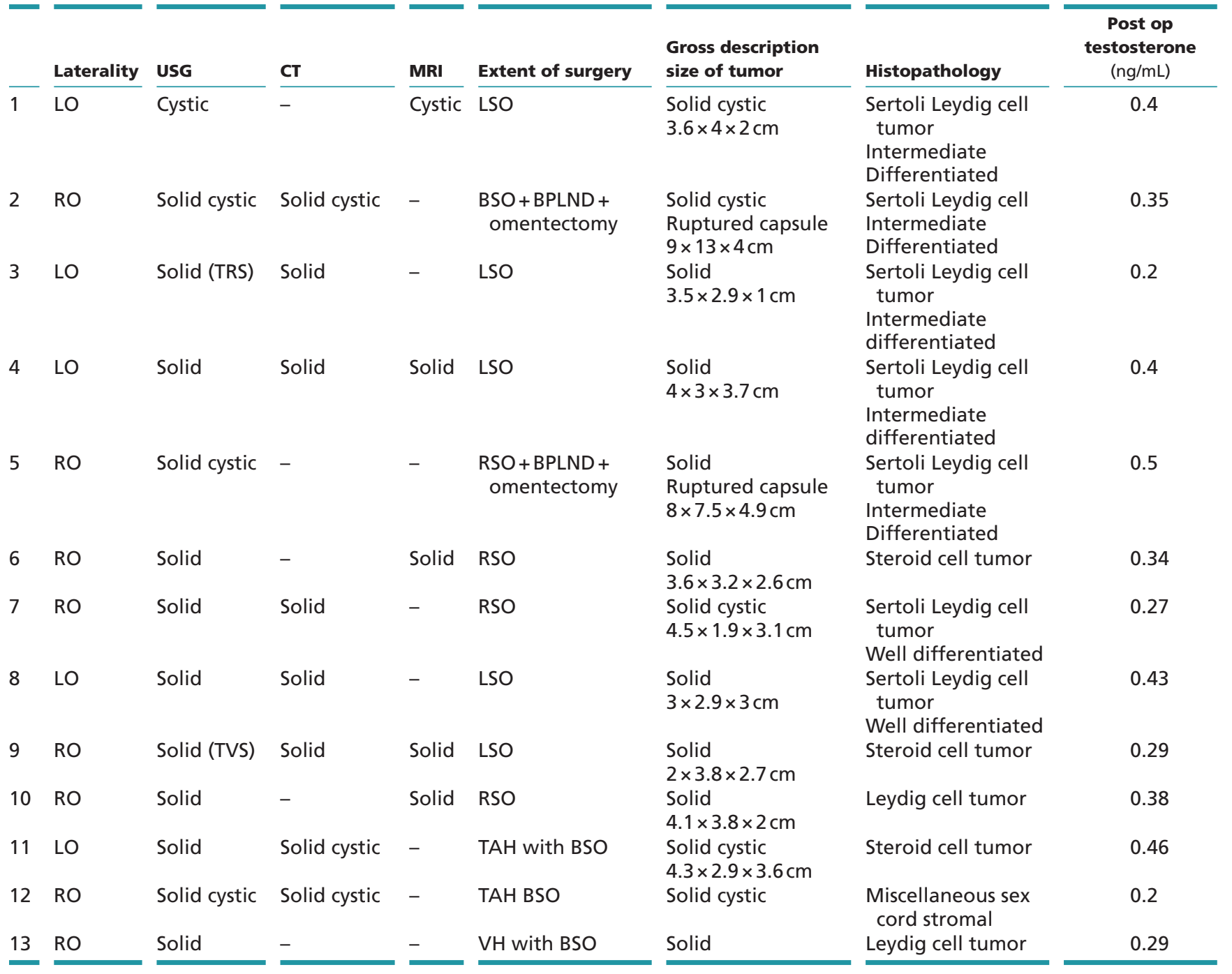

BPLND, bilateral pelvic lymph node dissection; BSO, bilateral salpingo-opherectomy; CT, computed tomography; LO, left ovary; LSO, left salpingoopherectomy; MRI, magnetic resonance imaging; RO, right ovary; RSO, right salpingo-opherectomy; TAH, total abdominal hysterectomy; TRS, transrectal sonogram; TVS, transvaginal sonogram; USG, ultrasonography; VH, vaginal hysterectomy.

of $\leq 12$ months, four patients had symptom duration of 3-4 years. This may be due to late presentation of few VOT patients in our study. Nevertheless, none of the patients in our study presented with palpable abdominal mass or pain which contrasts with the presentation of epithelial ovarian tumors. This may be due to early diagnosis of functional tumors. Though in literature, patients with Sertoli Leydig cell tumor have presented with hyperestrogenic manifestations, none of our patients had those features (4).

Although all patients had severe hyperandrogenemia, pattern of virilisation varied and there was no significant correlation between serum total testosterone and $\mathrm{mFG}$ or any other feature of virilisation. This suggests that

$\begin{array}{lr}\text { https://ec.bioscientifica.com } & \text { ○ } 2018 \text { The authors } \\ \text { https://doi.org/10.1530/EC-18-0360 } & \text { Published by Bioscientifica Ltd }\end{array}$

the sensitivity to elevated serum testosterone varies widely, not only among different women but also at different androgen-sensitive areas of the same woman (5). Modified $F$ and $G$ score was significantly higher in women with clitoromegaly suggesting the possibility of similar sensitivities of hair follicle and clitoris to androgens.

Hyperandrogenemia in postmenopausal women is a rare condition. Postmenopausal HA can be tumor- or nontumor related, with pathology residing either in the ovary or adrenal gland (6). Ovarian hyperthecosis $(\mathrm{OH})$ and VOT are most common causes of HA in these patients (7). It may be challenging to differentiate between VOT and $\mathrm{OH}$ as there can be a considerable overlap in their presentation. One study showed that the age of presentation, onset and

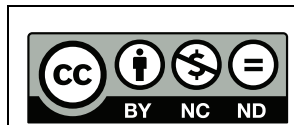

This work is licensed under a Creative Commons Attribution-NonCommercial-NoDerivatives 4.0 International License. 


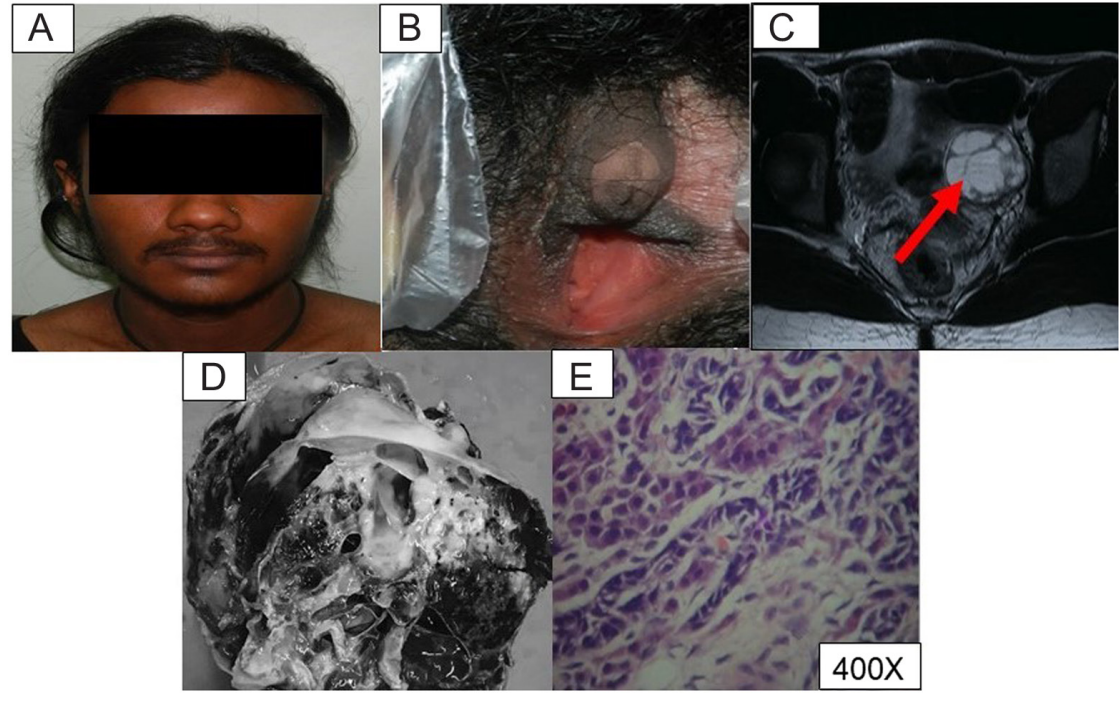

Figure 3

Sertoli Leydig cell tumor: Hirsutism (A) and clitoromegaly, clitoral index: $1 \mathrm{~cm}^{2}(B)$; magnetic resonance imaging (T2)-hyperintense, multiloculated, cystic lesion with septae within (C); $13 \times 9 \times 4 \mathrm{~cm}$ solid cystic mass with rupture of capsule (D); microscopy showing tubules composed of Sertoli cells with interspersed small clusters of Leydig cells (400x) (E). duration of symptoms, presence of hirsutism, alopecia and clitoromegaly do not help to differentiate the two conditions but presence of change in voice and muscle hypertrophy favor the diagnosis of VOT over $\mathrm{OH}$. In our study also both the postmenopausal women had deepening of the voice. In addition, both the patients had breast atrophy. However, the latter finding is unlikely to differentiate the two conditions since the estrogen deficiency in postmenopausal women is more likely to contribute to breast atrophy than hyperandrogenemia.

Degree of serum testosterone elevation can be useful for diagnosis of cause of HA. It is very uncommon for PCOS to have testosterone level $>1.5 \mathrm{ng} / \mathrm{mL}$ (8), whereas serum total testosterone level $>2 \mathrm{ng} / \mathrm{mL}$ or more than $2-3$ times the upper normal range in most of VOT (9). All patients in our series have testosterone $>2 \mathrm{ng} / \mathrm{mL}$ which is in agreement with the previous literature. Thus, in virilised patient with serum testosterone $>2 \mathrm{ng} / \mathrm{mL}$ with normal DHEAS levels and no evidence of $21-\alpha$ hydroxylase deficiency are strong indicators of VOT (10). Study done by Hai Yan Zhang found that the median level of testosterone concentration was as high as $9.75 \pm 6.86 \mathrm{ng} / \mathrm{mL}$ (range 3.6$21.9 \mathrm{ng} / \mathrm{mL}$ ) before excision of VOT and reduced to normal level with in the 10 days after the surgery (11). Although lower serum total testosterone cut-offs $(1.0-1.4 \mathrm{ng} / \mathrm{mL})$ (12) have been suggested to differentiate $\mathrm{OH}$ and VOT in postmenopausal women, a recent study by Yance et al. questioned diagnostic accuracy of these cut-offs. In fact, the study demonstrated that one-third of women with $\mathrm{OH}$ may have a testosterone greater than the classical cutoff $(2 \mathrm{ng} / \mathrm{mL})$, questioning the accuracy of this higher cutoff also. In their study the best discriminating serum total testosterone level was $3.12 \mathrm{ng} / \mathrm{mL}$. However, this cut-off had sensitivity of $76.9 \%$ for VOT which suggested that use of this cut-off may miss nearly one-fourth of VOT. Hence, use of the classical cut-offs $(2 \mathrm{ng} / \mathrm{mL}$ or $1.5 \mathrm{ng} / \mathrm{mL})$ may yield better sensitivity.

None of the patients in our series had suppression of gonadotropins despite severe hyperandrogenemia. There is no evidence of gonadotropin suppression by VOT so far $(13,14)$. However, both postmenopausal women with VOT in our study had low-normal gonadotropins for the postmenopausal status. FSH level $<35 \mathrm{mIU} / \mathrm{mL}$ has been suggested to favor the diagnosis of VOT in postmenopausal women (15) which was observed in both of our patients. However, the study by Yance et al. (12) demonstrated best discriminating FSH level as $22.3 \mathrm{mIU} /$ $\mathrm{mL}$ but again compromising the sensitivity to $77 \%$. Use of this cut-off would have missed both of our patients. Hence, use of a higher FSH cut-off $(35 \mathrm{mIU} / \mathrm{mL})$ may have higher sensitivity for VOT.

Ultrasound (US) is often the first imaging study performed in the evaluation of a suspected ovarian lesion because it is widely available, well accepted by patients, non-invasive and of low cost. Transabdominal sonogram could detect the tumor in all patients except one in whom the lesion was detected by TRS. This suggests TRS as a more sensitive imaging modality for diagnosis of VOT than TAS. Although transvaginal USG provides better diagnostic sensitivities, it was not performed in our patient with negative transabdominal USG since she was unmarried. Although, TAS had high sensitivity, it completely missed the lesion in one and cystic or solid component of the solid cystic tumors in three. All our patients underwent additional imaging (CT pelvis or MRI pelvis) as a part of preoperative mapping of the disease. CT/MRI not only 


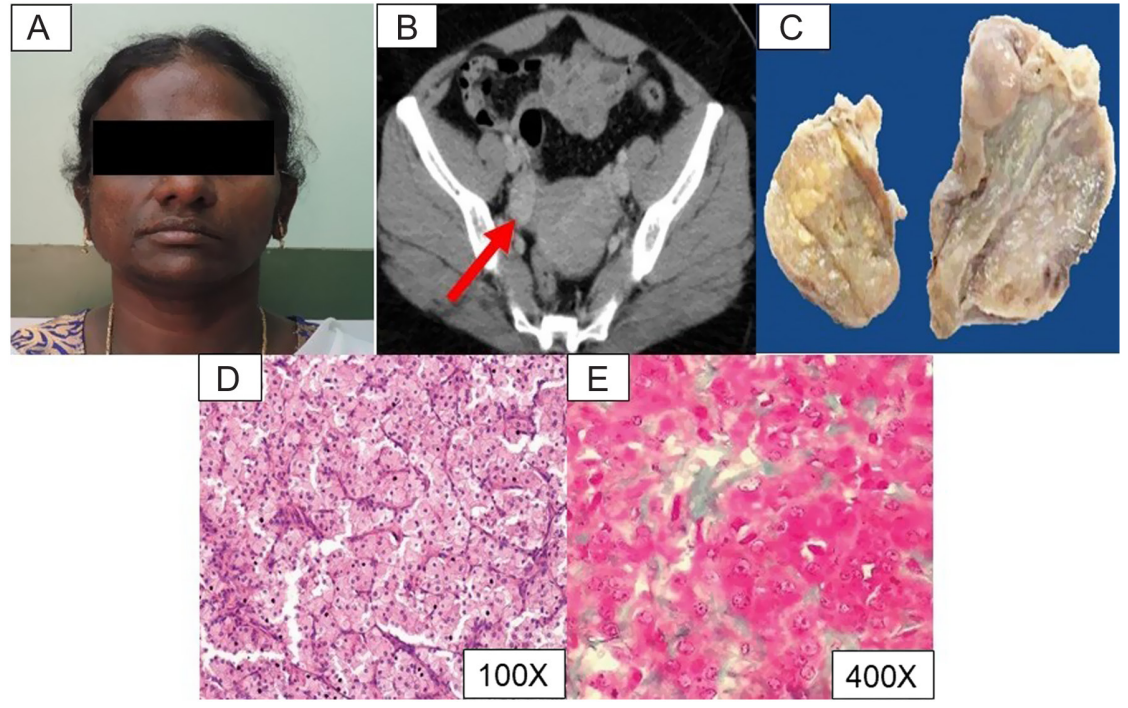

\section{Figure 4}

Leydig cell tumor: temporal recession of hairline (A); computed tomography: solid lesion in right adnexa $(2.1 \mathrm{~cm} \times 2.5 \mathrm{~cm})(B) ; 4.1 \times 3.8 \times 2 \mathrm{~cm}$ solid tumor with multiple yellow colored, irregular nodules (C); microscopy-round to polygonal cells with vesicular to hyperchromatic nuclei and abundant amount of granular cytoplasm (100x) (D); Masson's trichrome stain showing intracytoplasmic rods with blunt tapered ends (Reinke crystalloids) (E). detected the tumor missed by TAS but also detected the missed cystic components of the solid cystic tumors. In a study done by Yan Liu et al., the sensitivity, specificity and accuracy of combined application of ultrasound and CT were 89, 94.7 and 91.7\% (16), which were higher than those of either ultrasound or CT in the diagnosis of pelvic mass. In the evaluation of adnexal masses indeterminate on ultrasound, assessment with contrast-enhanced MRI increases sensitivity to $81 \%$ and specificity to $98 \%$. Hence, combined application of USG and CT scan/MRI has incremental value in accurate diagnosis of pelvic mass.

Surgery is the main stay of treatment. Decision about the extent of surgery is guided by stage of tumor, differentiation and future fertility. Fertility-sparing surgery (unilateral salpingo-oophorectomy) with or without standard staging surgery or total abdominal hysterectomy with bilateral oophorectomy are the various surgical approaches $(17,18)$. Brown et al. reported 31 patients affected by SLCT and five had their lymph nodes removed. None had positive nodes. 9/31 (28\%) recurrence and none had nodal metastases at the time of recurrence. Authors concluded that lymph node metastases are rare, and lymphadenectomy may be omitted during the staging procedure (19). As observed in our study postmenopausal women are usually treated with concomitant hysterectomy with bilateral salpingooophorectomy whereas those with ruptured capsule are subjected to BPLND and omentectomy with uni- or bilateral salpingo-oophorectomy. In our cohort, 11 patients underwent laparotomy and 2 underwent laparoscopy. A retrospective analysis of Sertoli Leydig cell tumors showed that although surgical effects are similar between laparotomy and laparoscopy, the latter had advantages in terms of cost, blood loss and postoperative recovery (4). Due to limited information about the effectiveness of postoperative therapy, adjuvant therapy remains questionable and requires further evaluation. However, current accepted treatment recommendations are to treat with platinumbased adjuvant chemotherapy any patient with grade 2-3 disease, any patient with an advanced stage disease and any patient with heterologous elements (20). Radiotherapy is of unknown beneficial value. None of the patients in our study were subjected to chemo- or radiotherapy.

In our study, Sertoli Leydig cell tumor was the most common cause of VOT which is in accordance with the previous literature. As observed in our study these tumors occur at relatively younger age than Leydig cell tumors. All Sertoli Leydig cell tumors were well or intermediately differentiated. None of the VOT in our series was malignant. Neither the type nor the differentiation of the tumor had any effect on serum testosterone level or degree of virilisation. Serum total testosterone level had correlation with tumor volume rather than histological subtype.

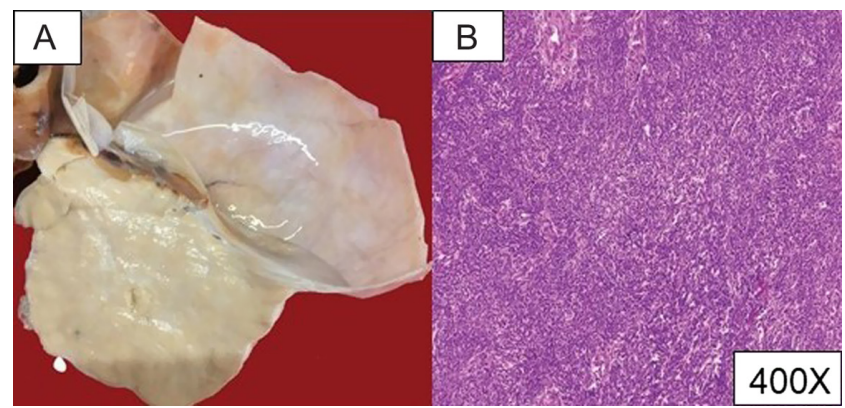

Figure 5

Sex cord stromal ovarian tumor (A) (unclassified variety) with microscopy showing oval to spindle shaped nuclei with scanty cytoplasm and indistinct cell membrane arranged in sheets (100x) (B). 
During the follow-up of these patients, after the tumor removal, patients noticed improvement in their symptom complex and there was a documented fall in the testosterone levels to the normal range in the postoperative period with improvement in their hyperandrogenic symptoms. Although voice change is considered as an irreversible symptom of HA, many of our patients reported partial improvement in voice.

The study was limited by small number of subjects. However, it is relatively a good sample size for a rare disorder like VOT, that too from a single center. The study was also limited by the retrospective design.

\section{Conclusion}

VOTs present with severe hyperandrogenism and hyperandrogenemia. Hyperandrogenemia correlates with tumor volume. VOT are either solid or solid cystic and Sertoli Leydig cell tumor is the most common histological subtype.

\section{Declaration of interest}

The authors declare that there is no conflict of interest that could be perceived as prejudicing the impartiality of the research reported.

\section{Funding}

This research did not receive any specific grant from any funding agency in the public, commercial or not-for-profit sector.

\section{References}

1 Colombo N, Peiretti M, Garbi A, Carinelli S, Marini C, Sessa C \& ESMO Guidelines Working Group. Non-epithelial ovarian cancer: ESMO Clinical Practice Guidelines for diagnosis, treatment and follow-up. Annals of Oncology 201223 (Supplement 7) 20-26. (https://doi.org/10.1093/annonc/mds223)

2 Young RH, Dickersin GR \& Scully RE. Juvenile granulosa cell tumor of the ovary. A clinicopathological analysis of 125 cases. American Journal of Surgical Pathology 19848 575-596. (https://doi. org/10.1097/00000478-198408000-00002)

3 Rosenfield RL. Clinical practice. Hirsutism. New England Journal of Medicine 2005353 2578-2588. (https://doi.org/10.1056/NEJMcp033496)

4 Zhang HY, Zhu JE, Huang W \& Zhu J. Clinicopathologic features of ovarian Sertoli-Leydig cell tumors. International Journal of Clinical and Experimental Pathology 20147 6956-6964.

5 Rosenfield RL \& Deplewski D. Role of androgens in the developmental biology of the pilosebaceous unit. American Journal of Medicine 199598 80S-88S. (https://doi.org/10.1016/S0002-9343(99)80063-1)

6 Mamoojee Y, Ganguri M, Taylor N \& Quinton R. Clinical Case Seminar: postmenopausal androgen excess-challenges in diagnostic work-up and management of ovarian thecosis. Clinical Endocrinology 201888 13-20. (https://doi.org/10.1111/cen.13492)

7 Alpañés M, González-Casbas JM, Sánchez J, Pián H \& EscobarMorreale HF. Management of postmenopausal virilization. Journal of Clinical Endocrinology and Metabolism 201297 2584-2588. (https:// doi.org/10.1210/jc.2012-1683)

8 Azziz R, Sanchez LA, Knochenhauer ES, Moran C, Lazenby J, Stephens KC, Taylor K \& Boots LR. Androgen excess in women: experience with over 1000 consecutive patients. Journal of Clinical Endocrinology and Metabolism 200489 453-462. (https://doi. org/10.1210/jc.2003-031122)

9 Moltz L, Schwartz U, Sörensen R, Pickartz H \& Hammerstein J. Ovarian and adrenal vein steroids in patients with nonneoplastic hyperandrogenism: selective catheterization findings. Fertility and Sterility 198442 69-75. (https://doi.org/10.1016/S0015-0282(16)47960-4)

10 Hunter MH \& Carek PJ. Evaluation and treatment of women with hirsutism. American Family Physician 200367 2565-2572.

11 Zhang H-Y, Zhu J-E, Huang W \& Zhu J. Clinicopathologic features of ovarian Sertoli-Leydig cell tumors. International Journal of Clinical and Experimental Pathology 20147 6956-6964.

12 Yance VRV, Marcondes JAM, Rocha MP, Barcellos CRG, Dantas WS, Avila AFA, Baroni RH, Carvalho FM, Hayashida SAY, Mendonca BB, et al. Discriminating between virilizing ovary tumors and ovary hyperthecosis in postmenopausal women: clinical data, hormonal profiles and image studies. European Journal of Endocrinology $2017 \mathbf{1 7 7}$ 93-102. (https://doi.org/10.1530/EJE-17-0111)

13 Pascale MM, Pugeat M, Roberts M, Rousset H, Déchaud H, Dutrieux-Berger N \& Tourniaire J. Androgen suppressive effect of GnRH agonist in ovarian hyperthecosis and virilizing tumours. Clinical Endocrinology 199441 571-576. (https://doi. org/10.1111/j.1365-2265.1994.tb01820.x)

14 Azziz R, Nestler JE \& Dewally D. In Contemporary Endocrinology: Androgen Excess Disorders in Women: Polycystic Ovary Syndrome and Other Disorders, 2nd Edn. Totowa, NJ, USA: Humana Press Inc., 2007.

15 Sarfati J, Bachelot A, Coussieu C, Meduri G, Touraine P \& Study Group Hyperandrogenism in Postmenopausal Women. Impact of clinical, hormonal, radiological, immunohistochemical studies on the diagnosis of postmenopausal hyperandrogenism. European Journal of Endocrinology 2011165 779-788. (https://doi.org/10.1530/EJE-11-0542)

16 Liu Y, Zhang H, Li X \& Qi G. Combined application of ultrasound and CT increased diagnostic value in female patients with pelvic masses. Computational and Mathematical methods in Medicine 2016 2016 6146901. (https://doi.org/10.1155/2016/6146901)

17 Zhang M, Cheung MK, Shin JY, Kapp DS, Husain A, Teng NN, Berek JS, Osann K \& Chan JK. Prognostic factors responsible for survival in sex cord stromal tumors of the ovary - an analysis of 376 women. Gynecologic Oncology 2007 104 396-400. (https://doi. org/10.1016/j.ygyno.2006.08.032)

18 Bhat RA, Lim YK, Chia YN \& Yam KL. Sertoli-Leydig cell tumor of the ovary: analysis of a single institution database. Journal of Obstetrics and Gynaecology Research 201339 305-310. (https://doi.org/10.1111/ j.1447-0756.2012.01928.x)

19 Brown J, Sood AK, Deavers MT, Milojevic L \& Gershenson DM. Patterns of metastasis in sex cord-stromal tumors of the ovary: can routine staging lymphadenectomy be omitted? Gynecologic Oncology 2009113 86-90. (https://doi.org/10.1016/j.ygyno.2008.12.007)

20 Sigismondi C, Gadducci A, Lorusso D, Candiani M, Breda E, Raspagliesi F, Cormio G, Marinaccio M \& Mangili G. Ovarian SertoliLeydig cell tumors. A retrospective MITO study. Gynecology Oncology 2012125 673-676. (https://doi.org/10.1016/j.ygyno.2012.03.024) (c) 2018 The authors Published by Bioscientifica Ltd
Received in final form 4 October 2018

Accepted 30 October 2018

Accepted Preprint published online 1 November 2018

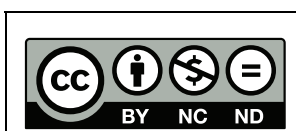

This work is licensed under a Creative Commons Attribution-NonCommercial-NoDerivatives 4.0 International License. 